\title{
PRESENÇA DO BRASIL NO ARQUIVO DA ACADEMIA DAS CIÊNCIAS DE LISBOA: CATÁLOGO SELETIVO DA SERIE AZUL DE MANUSCRITOS
}

Helotsa Liberalli Bellotto(*)

\begin{abstract}
A Academia de Ciéncias de Lisboa possui considerável e precioso acervo documental, abrangendo livros, manuscritos e objetos de incalculável valor e relevância para a história dos estudos literários, filosoficos, históricos, religiosos, sociais e da ciência e da técnica em geral, em seus aspectos universais, como tambem para a historia de Portugal e de todos os palses que originariamente integravam o império colonial lusitano como provincias ultramarinas.
\end{abstract}

Tendo herdado a biblioteca do antigo Convento de Jesus (prédio onde hoje se acha instalada), a Academia teve este material acrescido de outros espolios institucionais ou pessoais, de doaçōes avulsas e dos documentos decorrentes do proprio evoluir da vida academica, fossem os ali produzidos, fossem os acumulados/recebidos em funçáo das atividades da instituiçăo, desde a sua fundaçăo em 1784.

Dentre essa documentaçăo há duas coleçōes de manuscritos tăo heterogeneas quanto ricas em informaçóes de interesse historico conhecidas como Série Vermelha e Série Azul. A primeira já conta, desde alguns anos, com extenso Catálogo. A segunda so possui para sua identificaçáo um antigo fichário, contendo dados básicos (autor, título, data, paginaçáa), ordenados em sequencia numérica aleatória e no qual nem autores, nem assuntos acham-se reunidos.

O processo descritivo unitário, portanto, o que resulta num catálogo, é o melhor aplićável à Série Azul. O objetivo náo é abarcar a

- Professora da Faculdade de Estudos Sociais Aplicados, UnB. 
totalidade dos 1946 "Manuscritos" (codices autenticos e inautenticos ou maços) que compбem a Série. Seus conteúdos apresentam-se bastante diversificados, relacionando-se as áreas de Letras, Religião, Filosofia, Ciencias puras e aplicadas, Política, Historia, etc. Por isso é mais logico e útil para a pesquisa que os documentos sejam acessados por meio de catálogos parciais. Além disso, a tipologia documental e muito heterogenea. Năo integram a Série Azul só as memórias apresentadas a Academia (tanto por socios nas sessoes académicas como aquelas apresentadas em seus concursos anuais por pessoas náo partícipes de seu corpo societário de cientistas); integra-a também, uma grande variedade tipologica, entre os documentos oriundos de doaçoes de arquivos pessoais e de entidades, em grandes conjuntos ou avulsos, ocorrendo, outrossim, material relativo à administraçáo e funcionamento cotidiano da Academia das Ciencias e Letras de Lisboa.

Na escolha do tema deste Catálogo optou-se por contribuir para o esforço que o Brasil vem empreendendo de uns anos para ca, por meio de vários pesquisadores e instituiçoes, de levantar informaçóes sobre a documentaçăo, de interesse para a sua história, existente no exterior.

Assim, foram analisados todos os documentos possuidores de dados relevantes para a historia polftica, social, económica e cientffica do pals, deixando-se de lado, no entanto, os que, embora de autoria e temática brasileiras, sáo de conteúdo literário, religioso, artistico ou filosofico. Estas memorias poderăo ser objeto de futuros catálogos que venham a facilitar a pesquisa nestas áreas.

A metodologia foi a preconizada pela teoria da descriçáo documental para o caso de coleçoes. A Série Azul é uma coleçáo e năo um fundo. Entenda-se por coleçáo a um conjunto de documentos que podem ser manuscritos ou impressos, antigos ou recentes, textuais ou iconograficos, mas cuja grande característica é a de constituirem uma reuniáo artificial. Nesta, os componentes săo "colecionados" por razoes especialmente cientlficas ou culturais, com materiais de diferentes proveniencias e com diferentes funçóes. Já o fundo vem a ser um conjunto de documentos produzidos e/ou acumulados por uma entidade pública ou privada, no exercício das funçóes que justificam a sua existência, guardando os papéis relaçoes orgânicas entre si e conservados, em primeira instancia, por razðes jurldico-administrativas e, depois, passado o valor legal, por razoes culturais ou cientificas.

Diante destas conceituaçoes verifica-se que săo tipicos documentos de coleçáo os que constituem a maior parte da Série Azul. Mencione-se, contudo, que fazem parte deste conjunto alguns documentos que, na verdade, deveriam estar integrados ao Fundo da Academia de Ciencias de Lisboa, já que săo testemunhos náo só de suas atividadesmeio (as de caráter administrativo), como também de suas atividadesfins (as memórias e os pareceres). No entanto, dada a forma como es- 
tăo vinculados à coleçáo, dispersos de suas provávèis séries documentais advindas das antigas funçбes da Academia, descaracterizaram-se como documentos arquivisticos, podendo, por ora, serem processados como elementos de coleçăo.De outra parte, também há na Série Azul documentos pertencentes a espolios pessoais que, numa futura reordenaçăo, poderiam ser reunidos a seus congeneres, vindo a formar conjuntos homogeneos.

A montagem dos verbetes de um catálogo, correspondendo cada um a uma peça documental ou a um pequeno conjunto homogeneo, pode obedecer a critério cronológico, geográfico ou temático e subtemático. A escolha - sempre visando o interesse da pesquisa - recaiu sobre a ultima modalidade.

O formato do verbete obedece a entrada pelo título das memórias (que constituem a esmagadora maioria dos documentos da Série) seguindo-se a autoria, os conteúdos, as datas e paginaçăo. Entre parenteses, a informaçăo se se trata de codices ou maços (avulsos) e as medidas, considerando-se primeiramente a altura e depois a largura. Foram levados em conta indiferentemente os codices autenticos (livros em branco que recebiam a escrita) e códices inautenticos (encadernaçăo posterior de documentos já escritos). Por áltimo, figura no verbete a cota que remete ao número do Códice ou Maço, desígnado por Ms. No caso de Memórias heterogeneas, porem integrantes de um mesmo volume, foram designadas por seu número na sequencia, antecedido do número do códice.

Os documentos com interesse para a historia do Brasil foram agrupados em grandes temas selecionados a partir do próprio material. Seu conjunto representa uma variada contribuiçăo em áreas e épocas estudadas e pouco conhecidas. A importancia destes e dos demais documentos da Série Azul está em seu ineditismo e na sua variedade. Oxalá ește Catálogo possa contribuir para a sua divulgaçăo e utilizaçăo.

\section{I - HISTÓRIAS E NARRATIVAS \\ II - DESCRIÇĀO E VLAGENS \\ III - POLITICA E ECONOMLA \\ IV - ADMINISTRAÇĀO \\ V - FAUNA E FLORA \\ VI - INDfGENAS INDICE}

\section{I - HISTÓRIA E NARRATTVAS}

1 - Códice contendo cópia da "História da provincia de Sácta Cruz a qui vulgarmete chamamos Brasiln por Pero Magalhaes de Gandavo, na qual descreve a descoberta, a 
razáo de ser do nome, os lugares, os primeiros governantes, os moradores, a fauna, a flora e "as grandes riquezas que se esperăo da terra do sertáo". Lisboa, Officina de Antonio Gonçalves, 1576. 226p. Impresso. (Códice. Cópia manuscrita seculo XVIII. $213 \mathrm{~mm} \times 155 \mathrm{~mm}$ ).

Ms 1780

2 - Códice contendo copia resumida do "Tratado da terra do Brazil na qual se contem a informaçáo das couzas que ha nestas partes por Pero de Magalháes", antecedido de uma introduçáo sobre o ineditismo deste texto do autor da "História da Província de Santa Cruz". A seqüencia é semelhante à original, isto $e$, por capitanias, porém com os dados resumidos pelo compilador. c. 1576. 45p. (Códice. Cópia século XIX. 308mm x 215mm).

Ms 739

3 - Cópia da memória intitulada "História da Capitania da Parafba", em duas versóes, cuja sucessáo de vinte e três capítulos mostra a atuaçāo dos primeiros conquistadores, a questáo dos limites de Tordesilhas, e faz a descrição da costa do Brasil, desde o extremo norte até a Paraíba, trazendo textos identificados pelos nomes dos diferentes grupos indigenas, aludindo aos costumes e modo de vida de cada um. Madrid, 1 de março de 1587.84 p. (Códice. Cópia do século XIX. $288 \mathrm{~mm}$ x $205 \mathrm{~mm}$ ).

Ms 133

4 - Memória em đuas versóes intitulada "Compêndio historial de la jornada del Brazil y sucessos della. Donde se da cuenta de como gano el rebelde olandez la ciudad del Salvador y Bahia de todos los sanctos y de su restauración por las Armadas de Espaná..." por Juan de Valencia y Gusman que desenvolve, em 14 capítulos, a narrativa da invasao holandesa na Bahia. Principia por dados gerais sobre o Brasil, quem o descobriu, a terra e a gente; relata, a seguir, a chegada dos holandeses à costa e o ataque, saque e ocupaçáo de Salvador; trajeto e composição da armada espanhola que veio em socorro, desde a sua saída de Lisboa até o sítio de Salvador, o choque, a rendiçáo, a ocupaçăo e o retorno a Espanha. 1626. 225p. + 148p. (Codice. $315 \mathrm{~mm} \times 220 \mathrm{~mm}$ e $212 \mathrm{~mm} \times 150 \mathrm{~mm}$ ).

Ms 286 e Ms 382.1

5 - "Memórias para a História da Capitania de S. Vicente, hoje chamada de Sáo Paulo do Brazil" por Frei Gaspar da Madre de Deus, em que são descritas a fundação e a evoluçāo da Capitania de Săo Vicente, da vila de Nossa Senhora da Conceiçăo de Itanhaém e da Capitania de Santo Aimaro. 
1786. 297p. com correçðes e marginália. (Códice. $295 \mathrm{~mm} \mathrm{x}$ $210 \mathrm{~mm})$.

6 - Códice contendo, entre outros, um dossię intitulado: "Historia das conjuraçoens acontecidas em diversos tempos com o Reyno de Portugal" e no qual um dos tópicos é de interesse dos estudos brasileiros: a cópia da "Sentença que os da Alçada do Rio de Janeiro profferiráo contra os Reos de Alta Traiçăo e Rebeliăo em 18 de março de 1792 pela rebeliáo que intentavåo fazer nas Minas Geraes..." 244p. (Códice. 285mm x 190mm).

Ms 134

7 - Códice contendo, entre outras, a "Memoria sobre a Capitania do Rio Grande do Sul ou a influencia da conquista de Buenos Ayres pelos ingleses em toda a América e meios de prevenir seus effeitos" por Luiz Beltráo Gouveia D'Almeida. Carapito, 10 de novembro de 1806. (Compilado pelo Coronel J.P. Cardoso Giraldes na sua "Colleçăo de manuscritos importantes"). (Códice. 310 mm x 205mm).

Ms 648

8 - Códice contendo "Memoria sobre o descobrimento da Capitania de Goiaz" pelo Padre Luis da Silva e Sousa relatando o seu descobrimento, sua populaçăo, as receitas $\mathrm{e}$ despesas, citando governadores, ouvidores e provedores que atuaram naquela Capitania. Vila Boa, 30 de setembro de 1812. 122p. (CÓdice. 289mm x 195mm).

Ms 1754-A

9 - Memoria intitulada "Estatistica histórica geografica Da Provincia do Maranháo" por Antonio Bernardino Pereira do Lago, coronel do Corpo de Engenheiros naquela província e apresentada à Comissáo de Estatística do Congresso das Cortes Gerais portuguesas. Descreve a evoluçăo da populaçáa, o "estado militar, eclesiástico e político" do Maranhão, bem como a sua agricultura, fauna, flora, indústria e comércio, contendo mapas estatisticos relativos a cada um desses aspectos". Maranhão, 30 de março de 1822. 133p. (Maço. 260mm x 200mm).

Ms 161

10 - Memoria intitulada "Um caso de atavismo mysticoreligioso na historia luso-brasileira. O reino encantado d'EI Rey Dom Sebastiåo nos sertōes de Pernambuco (1835-38)" por Egas Moniz Barreto de Aragáo, da Academia de Medicina da Bahia, na qual em oito capítulos aborda a psicologia do sertanejo brasileiro, estudando o fanatismo sebastianista 
em torno do Padre Francisco Correia, em Pedra Bonita. Relata as açōes da seita e a repressão governamental. s.d. 106p. (Códice. $320 \mathrm{~mm} \times 215 \mathrm{~mm}$ ).

Ms $\mathbf{1 0 0 0}$

11 - Memoria intitulada "As primeiras narrativas do descobrimento do Brasil" por Francisco Marques de Sousa Viterbo, que afirma serem duas e de publicaçáo quase simultanea por Fernăo Lopes de Castaneda e por Joåo de Barros. Reconhece que ambas se detiveram mais em informaçóes sobre a fndia. Compara os dados quanto ao dia da chegada $e$ as primeiras providencias de Pedro Álvares Cabral. 7 de fevereiro de 1902. 16p. com correçōes e marginália. (Maço. $320 \mathrm{~mm} \times 110 \mathrm{~mm}$ ).

Ms 1310

12 - Memoria intitulada "Quando chegou D. João VI ao Brasil?" onde se pretende provar o erro de se consagrar o 20 de janeiro de 1808 como o da chegada da Família Real à Bahia, argumentando pela fixaçăo do dia 24 do mesmo mes. Sem autor e sem data. 5p. (Maço. $320 \mathrm{~mm} \times 220 \mathrm{~mm}$ ).

Ms 1344

13 - Memoria intitulada "O Instituto Histórico do Brazil" por Pedro Wenceslau Brito Aranha relatando seu aparecimento em 1827, dentro da Sociedade Auxiliadora da Indústria Nacional e o desenrolar das primeiras reuniós; alude a outros estabelecimentos culturais, inclusive a $\mathrm{BI}$ blioteca nacional brasileira, dizendo da sua importancia para o pals.s.d. 18p. com correçőes. (Maço. 230mm x 175mm).

Ms 1595

\section{II - DESCRIÇÃO E VIAGENS}

14 - Roteiro de navegaçăo e descriçăo, em frances, intitulado "Instruction hydrographique de la coste du Brésil, comprise depuis le Cap de St. Augustin (...) jusqu'au Cap. Hoorne (...) accompagné des plans, et profils des ports, havres, isles et autres objetcts..." por Dupre Ebrard e contendo instruçoes desde a França até a Madeira, as Canárias e a Cabo Verde e dal a Pernambuco e o resto da costa brasileira. Planta e perfil de várias ilhas. Saint Malo, 1o. de março de 1711. 40 p. ilus. (Códice. $330 \mathrm{~mm}$ x 220mm). 
15 - Roteiro de navegaçăo e descriçăo de viagem intitulado "Roteíro chorografico da viagem (...) ao Rio Amazonas em a parte que fica compreendida na Capitania do Gram Pará, tudo em destino de ocularmente observar e socorrer a Praça, Fortalezas e Povoaçoes que lhes săo confrontantes" pelo Sargento Mor Engenheiro Jodo Vasco Manoel de Braun, que descreve, dia a dia, as etapas da viagem e, em notas de rodapé, caracteriza as localidades e acidentes geográficos citados no texto. De 18 de setembro a 7 de novembro de $1784.80 \mathrm{p}$. (Códice. $345 \mathrm{~mm} \times 215 \mathrm{~mm}$ ).

Ms 628

16 - Roteiro de navegaçăo e descrição de viagem intitulado "Roteiro Chorografico da viagem que se costuma fazer da cidade de Santa Maria de Bellem, capital do Gram Pará, a Villa Bella, Capital de Mato Grosso" por Joáo Vasco Manuel de Braun, Sargento Mor Engenheiro em que relata as três possibilidades para sair-se de Belém por via fluvial, passando a descrever o roterio pelo Rio Mojeu até Vila Bela, detalhando itinerários, as ilhas, o estado dos ancoradouros e dispensando as vilas e aos acidentes geográficos mais importantes. Extensas notas de rodape. 1784. 48p. (Códice. $330 \mathrm{~mm} \times 210 \mathrm{~mm}$ ).

Ms 284

17 - Memória intitulada "Descripçăo chorographica do Estado do Gram-Pará que por ordem alphabética descreveu Joáo Vasco Manoel de Braun, Governador da Praça de Macapá em o anno de 1789" em que constam: listagem de 126 nomes de vilas, povoaçб̄es, freguesias e rios; extenșos verbetes para cada vila; descriçăo detalhada dos rios e suplemento trazendo dados acessórios. 52p. (Codice. $330 \mathrm{~mm} \mathrm{x}$ $210 \mathrm{~mm}$ ).

Ms 485

18 - Diário da viagem de Francisco José de Lacerda e Almeida entre Vila Bela, na Capitania de Mato Grosso até Santos, na Capitania de Săo Paulo, descrevendo trajetos terrestres, navegaçðos, observaçoes e reconhecimentos de acidentes geográficos das Capitanias do Pará, Rio Negro, Mato Grosso e Săo Paulo. 1788-1790. 30p. e mapa com notas. (Códice. $360 \mathrm{~mm} \times 230 \mathrm{~mm}$ ).

Ms 998

19 - "Memória a respeito dos Rios Baures, Branco, da Conceiçăo, de Sáo Joaquim..." por Francisco José de Lacerda e Almeida, no qual o Autor faz referência à doaçáo que fez a Academia das Ciências do seu "Diário de viagem", 
pretendendo com o presente texto amplia-lo no concernente aos rios. 1780-1790. 13p. (Maço. 310mm x 210mm).

Ms 707

20 - Roteiro de navegaçoes e descriçăo de viagem intitulado "Derrota aprezentada a Academia Real da navegaçăo por Jose Partricio de Souza (...) que segue viagem desta Cidade de Lisboa para Pernambuco, neste anno de 1792..." trazendo as tabelas diárias de "ventos e velas" e distáncias desde 4 de novembro de 1792 a 2 de janeiro de 1793 . Contém ainda quadros de observaçoes de longitude e duas cartas hidrograficas nas quais o Autor demonstra erros em relaçăo a de Joannes van Keulen, feita em 1686, em Amsterdam. 1792. 24p. (Códice. 332mm x 214mm).

Ms 18

21 - Roteiro de navegaçáo e descriçăo de viagem intitulado "Diário náutico de Joaquim Joze Pereira Pinto seguindo viagem de Lisboa para Pernambuco ..." em que consta determinaçăo do ponto de partida e desenho da barra; e seguem-se os diários, por dia, em formulários impressos preenchidos relativamente a rumos, ventos, "abatimento, amura, derrota e variaçoes de agulha", além das tabelas de cálculo de longitude. 17 de dezembro de 1794 a 11 de fevereiro de 1795 (ida); 25 de março a 5 de junho de 1795 (volta). (Codice. $310 \mathrm{~mm} \times 210 \mathrm{~mm}$ ).

Ms 43-1

22 - "Carta Corographica que compreende a Barra ou entrada do Rio Grande de Sáo Pedro e o terreno que medeia a Freguezia do Estreiro, o Arroyo de Taim e Campos de Piratini nas vizin hanças do Serro Pelado..." por Manoel Muniz do Couto Reis c. 1799 (Mapa: aquarela e nanquim, 585mm x 925mm).

Ms 14-11

23 - Codice contendo a "Relaçáo das quatro visitas que fez em 1787 no Gram Pará D. Frei Caetano Brandăo, Bispo do mesmo Estado. Depois Arcebispo de Braga..." na qual aquele prelado, declarando querer ser útil aos Capitaes Generais, fá que nunca se deslocavam para fora das capitais, faz uma detalhada descriçáo dos lugares e de suas igrejas, da populaçăo de indios e "moradores", sua alimentaçáo, hábitos e o estado da agricultura. Braga, 1799. (Códice. $315 \mathrm{~mm}$ x $215 \mathrm{~mm}$ ).

Ms 477

24 - Cópia da memória intitulada "Parte sexta do Thesouro descuberto no Rio maximo Amazonas (...) offerecidas 
por hum curiozo aos navegantes" em dezoito capitulos que descrevem inventos a serem aperfeiçoados para a navegaçăo; engenhos de açúcar e aquedutos para o Rio Amazonas. s.d. 80p. (Cópia tirada em Evora em 5 de outubro de 1818 pelo Padre Cypriano Pereira do Alto). (Maço. 22mm x $164 \mathrm{~mm})$.

Ms 786

25 - Memoria intitulada "Descriçăo geognóstica da montanha de Arrassoiaba e sua vezinhança, assim tambem o principio da historia das Fabricas de ferro..." por Frederico Luiz Guilherme Varnhagen, dando: posiçáo geográfica, composiçăo química do terreno e histórico da extraçăo do ferro, desde a Sociedade fundada em 1770 até a época da gestáo do Autor, como seu diretor. Real Fábrica de Ferro de Săo Joăo de Ypanema, 2 de março de 1820. 8p. (Maço. 310mm x $215 \mathrm{~mm}$ ).

Ms 725

26 - "Memoria Topographica e Economica da Commarca de Ilheos" por Balthasar da Silva Lisboa, em oito capitulos trazendo a origem e importância, situaçăo, costumes, natureza do solo e flora de Sáo Jorge dos Ilhéus e de outras vilas do distrito. c. 1824. 385p. (Codice. 232mm x 190mm).

Ms 1764

27 - Memória intitulada "Inscripçăo da Fortaleza da Cidade do Ceará" por José Barbosa Canaes de Figueiredo Castello-Branco, reproduzindo o documento, em latim e traduzindo-o para o portugues, com comentários. Trata-se da inscriç̧oo de uma fortaleza construída em 1816 na "Villa da Fortaleza". Lisboa, 1o. de agosto de 1849. 1p. (Maço. $300 \mathrm{~mm} \times 210 \mathrm{~mm}$ ).

Ms 1370

28 - Códice contendo, na primeira parte, "Breve notícia dos principaes Rios do Estado do Brasil pertencente a Coroa de Portugal", com a descriçáo de dezoito rios, dando sua localizaçăo e caracteristicas. Sem autor e sem data. 344 p. (total). (Codice. $215 \mathrm{~mm}$ x $165 \mathrm{~mm}$ ).

Ms 333

28A - "Viagem filosofica a Serra de Ibiapaba na Capitania do Ceará por ordem de José Telles da Silva fez Joåo Machado Gois" dando descriçăo ffsica, geográfica, mineralógica, da fauna e da flora da regiáo. s.d. (Códice. $218 \mathrm{~mm} \mathrm{x}$ $160 \mathrm{~mm})$. 
28B - Roteiro de viagem intitulado "Relaçam Diaria da Viagem que fez para o Rio de Janeiro o Conte de Assumar, D. Pedro de Almeyda. 1717" e "Diario da jornada que o Excelentíssimo Senhor Dom Pedro desde o Rio de Janeiro athe a Cidade de Săo Paulo, e desta athe as Minas. Anno de 1717." Sem autor. (Codice. $212 \mathrm{~mm}$ x $150 \mathrm{~mm}$ ).

Ms 382.7 e Ms 382.8

28C - "Roteiro da viagem da Cidade do Pará e toda a sua Capitania athe aos confins do Rio Negro. Illustrado com algumas noticias que podem intereçar a curiozidade dos navegantes e dar mais claro conhecimento da dita Capitania". (Códice. $212 \mathrm{~mm}$ x 150mm).

Ms 382.11

\section{III - POLf́TICA E ECONOMIA}

29 - Cópia do "Traité de Paix et D'Amitié entre Louis XIV, Roi de France, et Jean V, Roi de Portugal Portant cession et renonciation de La Part de Sa Majesté Trés Chrétienne en faveur de Sa Majesté Portugaise, à toutes les terres appelées Cap du nord, à toutes celles des cótes de la Rivière des amasones, et a La navigation et commerce de cette Rivière, sous la garantie offerte et acceptee de la Reine de La Grande Bretagne fit a Utrecht Le 11 d'avril 1713" contendo introduçáo e dezenove cláusulas, seguidas dos instrumentos formais de concessáo de plenos poderes por parte de Luís XIV aos negociadores franceses e, por parte de D. Joao $\mathrm{V}$, aos negociadores portugueses, em frances e Iatim respectivamente. 1713. 14p. (Maço. 324mm x 205mm).

Ms 1111

30 - Códice cuja segunda parte contém cópia de documentos relativos a Montevideo e a Colonia de Sacramento, envolvendo questós diplomáticas entre Portugal e Espanha nos fins do século XVII e na primeira metade do século XVIII. 1682 - 1724. 348p. 18 peças documentais (Codice. $362 \mathrm{~mm} \times 230 \mathrm{~mm}$ ).

Ms 258

31 - Códice que reúne cópia e originais de documentos em portugues, espanhol, frances e latim, respeitantes direta ou indiretamente a Colonia do Sacramento, enviados em diferentes datas e de diferentes pontos da Europa a D. Luis da Cunha. Trata-se de correspondencia diplomática, relatos de acontecimentos no Prata, tratados entre Portugal e Es- 
panha, correspondencia de governadores da ColOnia do Sacramento e de Buenos Aires; manifestos, alvarás e instruçőes. 1713-1736. 24 peças documentais. 664p. (Códice. $335 \mathrm{~mm} \times 230 \mathrm{~mm}$ ).

Ms 19

32 - Códice contendo cópias de documentos em espanhol, frances, latim e portugues relativos aos limites da Colónia do Sacramento as hostilidades entre Portugal e Espanha no Prata. Contém muitas informaçóes sobre a açăo do governador de Buenos Aires reduzindo militarmente o termo daquele território, obedecendo o Tratado e que foi combatida pelo Governador de Colonia, com ajuda de tropas vindas da Bahia. 8 de agosto de 1713/21 de agosto de 1736. 188p. (Codice. $333 \mathrm{~mm} \times 218 \mathrm{~mm}$ ).

Ms 640

33 - Memória intitulada "Opulencia e cultura do Brazil nas Fabricas de Assucar, Tabaco, Ouro, Couro e Sola" dividida em quatro partes: 1 . "Opulencia do Brazil na lavra do assucar" em dez capítulos; 2 . "Cultura e Opulencia do Brazil na lavra do tabaco" em onze capítulos; 3 . "Cultura e opulencia do Brazil pelas minas de ouro" em dezessete capítulos; 4. "Cultura e opulencia do Brazil pela abundancia de gado, courama e outros contratos reaes que se rematao nesta conquista" em seis capítulos. Sem autor. 1762. 199p. (Códice. 201mm x 144mm).

Ms 391

34 - Códice intitulado "Coleçăo das ordens e instruçōens dadas a Roberto Mak Donall, encarregado da defeza do Porto de Santa Catarina...", coleçáo formada a partir da solicitaçăo de $D$. Maria I ao Marqués de Lavradio, vice-rei do Brazil, para instruir o processo de exoneraçăo de Macdonald do cargo de comandante da esquadra em Santa Catarina. 1775-1777 24p. (Códice. 348mm x 215mm) e Códice contendo processo mandado instaurar por Decreto de 7 de novembro de 1778 "contra o Coronel de-Mar Robert Mak Donall" para embasar seu julgamento por Conselho de Guerra, devido ao seu comportamento na defesa da Ilha de Santa Catarina. 1777-1778. 260p. (Códice. $214 \mathrm{~mm} \times 168 \mathrm{~mm}$ ).

Ms 630 e Ms 563

35 - Cartas de Antonio Luiz Pereira da Cunha, Marques de Inhambupe, ao Marques de Resende tratando da política interna platina e das relaçóes do Império brasileiro com as Provincias Unidas do Rio da Prata, que apresentavam dificuldades, já que Buenos Aires exigia que o Brasil renuncias- 
se a Provincia Cisplatina. Trata tambem de outros assuntos relativos a Corte Imperial, a morte da Imperatriz D. Leopoldina, entre eles. Rio de Janeiro, 17 de junho de 1826/22 de outubro de 1827. 3 peças documentais. (Maço. $315 \mathrm{~mm} \mathrm{x}$ $200 \mathrm{~mm}$ ).

Ms 1516

36 - Codice reunindo cartas escritas do Funchal, Rio de Janeiro, Paris, Londres e Bruxelas por diversos homens públicos ao Marques de Resende, todas respeitantes as lutas entre D.Pedro I e D. Miguel, envolvendo a legitimidade da coroaçăo de D. Maria II; alusठes tambem as pretensoes inglesas e as questoes diplomáticas, polfticas e pessoais. $11 \mathrm{de}$ junho de $1828 / 2$ de março de 1838 . 12 peças documentais. (Codice. $330 \mathrm{~mm} \times 215 \mathrm{~mm}$ ).

Ms 953

37 - Codice copiador contendo minutas de cartas do Marquês de Resende ao Marques de Barbacena, datadas de Paris e Londres, aludindo aos problemas politicos do Império Brasileiro, ao seu corpo diplomático na Europa, a politica francesa e austrfaca e as despesas feitas com D. Maria II, Rainha de Portugal. Londres, 29 de janeiro de 1829/Paris, 11 de abril de 1830.5 peças documentais.(Códice. $300 \mathrm{~mm} x$ $230 \mathrm{~mm})$.

Ms 965

38 - Codice copiador contendo minutas de cartas do Marques de Resende a José Bonifácio de Andrada e Silva, comentando questós ligadas à independencia do Brasil e às atitudes hostis de alguns portugueses; reitera a sua fidelidade a D. Pedro I. 16 de maio de $1832 /$ s.d. 2 peças documentais. (Codice. $280 \mathrm{~mm}$ x $220 \mathrm{~mm}$ ).

Ms 967

39 - Cartas do Marques de Maceio ao Marques de Resende, entáo Ministro Plenipotenciário do Brasil junto a Corte francesa, tratando de questoes diplomáticas, de polftica interna e externa do Império Brasileiro do Imperador apos a abdicaçăo. Viena, Turim, Genova. 21 de dezembro de 1829/8 de fevereiro de 1833.12 peças documentais. (Códice. $268 \mathrm{~mm} \times 210 \mathrm{~mm}$ ).

Ms 964

40 - Cartas de D. Pedro I, enquanto Imperador do Brasil e depois da abdicaçáo ao Marques de Resende datadas de Lisboa, Porto, Angra do Herofsmo e Rio de Janeiro, tratando:-dos tramites, na Europa, para o seu segundo casamento; de movimentaçăo de tropas, de apoio politico e de 
manifestos concernentes ao período de lutas contra D. Miguel. 21 de outubro de $1820 / 7$ de março de 1834 . 16 peças documentais. (Maço. 258mm x 200mm).

Ms 1518

41 - Cartas entre Christovão Pedro de Moraes Sarmento, Baráo da Torre de Moncorvo e o Marques de Resende, de cunho pessoal e cunho oficial, porém sigiloso, respeitante aos projetos de casamento de D. Pedro I Imperador do Brasil. Copenhague, 28 de outubro de 1828/Londres, 11 de fevereiro de 1848. 5 peças documentais. (Códice. $330 \mathrm{~mm} x$ $210 \mathrm{~mm}$ ).

Ms 954

42 - "Cartas de diferentes brasileiros para o Marques de Resende escritas de Paris, Gibraltar e Rio de Janeiro", tratando de concessáo de passaportes, comentários sobre a abdicaçăo de D. Pedro I e de cunho pessoal, com destaque para Francisco Ge de Acaiaba de Montezuma. 12 de maio de 1828/ 3 de outubro de 1854. 13 peças documentais. (Maço. $275 \mathrm{~mm} \times 220 \mathrm{~mm}$ ).

Ms 1517

43 - Memória intitulada "O Brazil e a emigraçăo" por Antonio Carlos Moreira Telles em que trata da colonizaçăo portuguesa na América, o problema da escravidăo negra vis-à-vis à emigração/imigraçăo. Detém-se nos casos de Săo Paulo e dos estados do sul. Aborda também as relaçōes luso-brasileiras quanto ao comercio e à imigraçăo. Novembro de 1913. 91p. (Maço. 295mm x 222mm).

Ms 1635

44 - Memoria intitulada "Brazil e Portugal" por Antonio Carlos Moreira Telles, tratando das relaçoes entre os dois palses no período imediatamente anterior e posterior à independéncia do Brasil, abordando comércio, navegaçăo e imigraçăo. Lisboa, junho de 1914. 89 p. (Maço $265 \mathrm{~mm} \mathrm{x}$ $210 \mathrm{~mm}$ ).

Ms 1634

45 - Memória intitulada "A emigraçăo Portuguesa para o Brazil"por Antonio Carlos Moreira Telles defendendo o Brasil de ataques que vinha sofrendo por parte da imprensa portuguesa a propósito dos emigrantes. Comenta as dificuldades para a realizaçăo de um tratado de comércio luso-brasileiro. Analisa o comércio, o trabalho e a emigraçăo, citan- 
do a alemá, a francesa, a italiana e a espanhola relativamente ao Brasil. Lisboa, maio de 1915. 26p. (Maço. 280mm x 210mm).

Ms 1642

46 - Cartas de Felisberto Caldeira Brandt, Marques de Barbacena, ao Marques de Resende datadas de Londres, de Laleham e do Rio de Janeiro, tratando: de rotina diplomática; das questoes entre D. Pedro e D. Miguel em torno da legitimidade da sucessão da coroa portuguesa; dos ajustes do casamento do Imperador do Brasil com Dona Amélia de Leuschtemberg e sua ida para o Rio de Janeiro. Alusóes, ainda à polftica européia e a intrigas palacianas. 28 de novembro de $1827 / 18$ de maio de 1830.28 peças documentais. (Maço. 258mm x 202mm).

Ms 1519

\section{IV - ADMINISTRAÇÄO}

47 - Códice contendo matéria vária numerada, destacando-se, no que toca ao Brasil, as de número: 25 - "Forma com que se estabeleceo a Casa da Moeda de Minas ou para melhor dizer, a sua perdiçăo..." 7p.; 37 - "Arbitrios que se derão a sua magestade o Senhor Rey Dom João o V acerca dos diamantes que se extrairăo no Serro do Frio, os quaes se detreminavāo recolher a hua Companhia..." 17p.; 38 - Resposta do Doutor Joăo Mendes de Almeida sobre "(...) se era conveniente fechar-se à mina delles e os extrahidos junta-los em uma Companhia..." e que foi negativa, vendo-se nisso a rulna do Reino. 14 p. (Códice. $288 \mathrm{~mm}$ x $200 \mathrm{~mm}$ ).

Ms 121

48 - Dossié intitulado "Questăo de competencia de despacho entre a Casa da India e a Alfândega sobre couros vindos de Buenos Aires e Colonia do Sacramento a Lisboa em a nao Nossa Senhora da Conceiçăo e Lusitania Grande" no qual há provas de que a Alfandega podia avocar-se a si o direito de receber o descarregamento dos couros para ali serem remetidos à Casa da India. 1751 32p.(incompleto) (Maço. 312mm x 212mm).

Ms 722

49 - Códice cartulário de documentos, notas e notícias referentes a Pernambuco contendo 460 peças documentais, 
entre elas: descriç5a do "Porto e sua barra"; cronologia, regimentos e obrigaçós dos governadores daquela Capitania; ordens régias quanto à sistemática da administraçăo local; regulamentaçáo do transporte transatlantico de soldados, religiosos e estrangeiros, além do de cartas, ouro, diamante e pedras preciosas; tópicos constitutivos das residências sobre atuaçăo dos capităes-mores; interdiçōes a comunicaçáo com Minas Gerais e atos normativos quanto a contratos, dizimos, despesas, rendimentos e arrecadaçáo sobre o tabaco. 1668-1746. 1290p. (Códice. 298mm x $210 \mathrm{~mm}$ ).

Ms 95

50 - Provisס̃es reais de D. Pedro II e de D. Joăo V, Reis de Portugal, dirigidas aos "Provedores dos defuntos e ausentes, capelas e residuos" que atuavam em várias partes do imperio português em África e Ásia, como também no Brasil, mencionando especialmente os de Pernambuco, Maranhao, Piaul, Parafba, Sergipe, Bahia, Ouro Preto, Sabará, Serro do Frio, Rio das Mortes, São Paulo, Santos, Rio de Janeiro e Rio Grande. 1690-1750. 293p. (Códice. 305mm x 210mm).

Ms 99

51 - "Mapa exactissimo de todos os moradores da Freguezia de São Pedro da Cidade da Bahia" trazendo número de casas; nomes, idades, estado civil, cor e ocupaçăo dos pais de família; nomes, idades das mulheres e filhos; número dos escravos, nome, idades e modo de vida dos agregados e de suas mulheres e filhos. Contém um pequeno texto comentando o levantamento. 1775.24 p. (Códice. $345 \mathrm{~mm} \times 217 \mathrm{~mm}$ ).

Ms 988

52 - Códice contendo "Cópia das ordens contheudas" no $4^{\circ}$, 59 e $6^{\circ}$ Livros de Registro da Alfândega do Rio de Janeiro, relativas a transporte de "fazendas e generos", contrabando, quantidades de carga de tabaco a transportar, taxas e impostos sobre a seda e outros produtos, cobrança de dividas, venda de pólvora, procedimentos de guardas, oficiais e escrivăes da Alfándega. Contém lista alfabética de produtos que seriam taxados, com os respectivos montantes. Lisboa, 28 de março de 1753/Rio de Janeiro, 22 de dezembro de 1799. 426p. (Códice. 52p).

Ms 215

53 - Códice copiador de cartas-régias, provisós e outros atos normativos de D.Joðo VI, enquanto Príncipe Regente e depois, Rei de Portugal, dirigidas a várias possessoes ultramarinas, incluindo ordens régias de soberanos anterio- 
res, mas ainda em vigor, quanto a autoridade, hierarquia e denominaçáo dos governadores coloniais. 1808-1820. 134p. (Codice. $310 \mathrm{~mm} \times 20 \mathrm{~mm}$ ).

Ms 488

54 - Codice copiador contendo correspondencia entre o Marquess de Santo Amaro e o Marqués de Resende, tratando de questoes politicas e administrativas, sobretudo relativas às relaçoes entre o Império Brasileiro e as Províncias Unidas do Rio da Prata. Rio de Janeiro, 2 de dezembro de 1825. 6 peças documentais. (Códice. $322 \mathrm{~mm} \times 204 \mathrm{~mm}$ ).

Ms 939

55 - Cartas de Miguel Calmon du Pin e Almeida, Marques de Abrantes, ao Marques de Resende sobre rotinas do serviço diplomático (instruçoes, nomeaçôes, despesas, emolụmentos, divisóes de consulados) e estudos e comentários sobre o estabelecimento de linhas maritimas regulares entre - Brasil e França e sobre retorno de estudantes brasileiros naquele pais, entre outros assuntos. Rio de Janeiro, 9 de dezembro de 1829 e 12 de junho de 1830.25 peças documentais. (Maço. 250mm x 200mm).

Ms 1510

56 - Comunicados de Mlguel Calmon du Pin e Almeida, Marques de Abrantes ao Marques de Santo Amaro transmitindo ordens de D.Pedro I, Imperador do Brasil, relativas a nomeaçóes, indenizaçð̋es, pagamentos e proibiçoes ligadas ao serviço diplomático das embaixadas e legaçoes do Brasil na Inglaterra, França e Portugal, Palácio do Rio de Janeiro, 19 de abril a 14 de setembro de 1830.8 peças documentais. (Maço. 250mm x $230 \mathrm{~mm}$ ).

Ms 948

57 - Conjunto de onze códices sob o título "Manuscritos do Coronel Giraldes. Miscellania" contendo vários trabalhos próprios e cópias de documentos feitas pelo Coronel J.P. Casado Cardoso Giraldes, havendo entre eles, alguns com interesse para os estudos brasileiros, a saber: v. 148 - notas sobre criaçăo de vilas, Justiça e tribunais, assim como cópias de leis e decretos relativos ao Brasil: v. 149 - quadro administrativo político, económico e financeiro do Brasil entre os anos de 1830 e 1838; 153 - dados biográficos de Pedro Álvares Cabral, descobridor do Brasil. 1807-1838. (Códice. 260mm x 205mm).

Ms 146 a Ms 156

58 -. Codice reunindo pareceres de autoria respectiva de Silvestre Pinheiro Ferreira, Felippe Ferrreira de Araujo e 
do Conde de Resende todos favoráveis aos direitos a seus bens no Brasil por parte de D. Pedro I, ex-Imperador do Brasil e da ex-Imperatriz Dona Amélia, contrariando o disposto pelo Tesouro Público imperial que exigia pagamento de despesas e se negava a executar as partilhas da herança do ex-Imperador, após a sua morte, o que beneficiaria a ex-Imperatriz viúva. 1832-1840. 27p. (Códice $320 \mathrm{~mm} \times 212 \mathrm{~mm}$ ).

Ms 943

59 - Memória sobre as minas de Cuiabá por Diogo de Toledo Lara Ordonhez em que comenta as lacunas da legislaçăo mineira e sugere inovaçóes quanto concessăo e partilha de terrenos auriferos s.d. 5p. (Maço. 340mm x 220mm).

Ms 1718

\section{V - FAUNA E FLORA}

60 - "Discurso do Doutor Duarte Ribeiro de Macedo sobre a transplantaçăo dos frutos da fndia ao Brasil que fes sendo enviado em França no ano de 1675". (incompleto).(Maço. Cópia do século XIX. 344mm x 214mm).

Ms 272

61 - Memória intitulada "Dizertaçam sobre a Coxonilha. História do seu descobrimento na América Portugueza" por José Henrique Ferreira, médico do Rio de Janeiro, que descreve detalhadamente sua geografia, importáncia económica e disseminaçăo no Brasil. 1772. 33p. (Maço. 350mm x $225 \mathrm{~mm}$ ).

Ms 1030

62 - "Memoria de algumas madeiras da Capitania da Bahia" por Theodosio da Silva Reboxo, contendo experiencias feitas com madeiras locais, contando com o incentivo do Governador e diante de testemunhas apresentando rol dos seus nomes. Há um quadro designando cada madeira, seu volume, dimensáo e o peso que suportou (ou năo). 1779-1780. 57p. (Códice. $215 \mathrm{~mm}$ x $163 \mathrm{~mm}$ ).

Ms 1789

63 - Memória intitulada "Descubrimento de acido Nitrozo ou Nitro" por Joaquim Jose Pereira que declara ter descoberto no Maranhăo, salitre que ele mesmo tratou quimicamente obtendo "cristaes alvissimos formados que afectarăo inteiramente hua configuraçăo romboidal..." 1796. 1p. (Códice. 330mm x 220mm). 
64 - "Memória sobre a plantaçáo dos algodóes, sua exportaçăo e decadéncia da lavoura da mandioca no termo da Villa de Camamú" por José de Sá Betancurt na qual dá a localizaçăo, o clima e as possibilidades agricolas variadas de Camamu afirmando que as dificuldades da cultura do algodáo, devido ao clima, seriam sanadas se a sua plantaçáo se interiorizasse mais, em direçăo ao Rio das Contas. 1798. 34p. (Maço. 218mm x 170mm).

Ms 1485

65 - Memória intitulada "Descripçáo botânica das Quineiras descobertas na Capitania do Rio de Janeiro pelo Capitâo Francisco José da Silveira, reconhecidas, classificadas e descriptas pelo Doutor Vicente Gomes da Silva". Anno de 1806". 12p. (Códice. 330m x 220mm).

Ms 17.45

66 - Memória intitulada "Descripçáo florestal de 158 differentes Arvores que crescem no certáo do Abaeté juntamente com huma colecçáo de madeiras das mesmas, oferecidas ao Real Muzeo do Rio de Janeiro" por Guilherme Barăo de Exchwege, dando nome e descrevendo, para cada espécie, as folhas, galhos, troncos, casca, madeira, uso e peso específico, sendo as árvores classificadas em duas grandes categorias: as sempre verdes e as que perdem folhas sazonalmente. Rio de Janeiro, 1898. 156p. (Maço. 247mm x 195 $\mathrm{mm})$.

Ms 1534

67 - Notas de estudo concentradas sob dois títulos: "A agricultura no Brasil - A época colonial" e "A Agricultura $e$ as indústrias no Brasil" por Antonio Carlos Moreira Teles, nas quais analisa as características e os rumos da questăo, desde os primeiros colonos até a época imperial mostrando, no segundo caso, a deficiencia dos produtos brasileiros na Europa. 1916. 145p. (Maço. 272mm x 208mm).

Ms 1630

68 - Códice contendo, na segunda parte, "Breve notfcia das principais Arvores de Fruto do Estado do Brasil", caracterizando 60 tipos. Sem autor e sem data. 344 p. (total). (Códice. $215 \mathrm{~mm} \times 165 \mathrm{~mm}$ ).

Ms 333

69 - Memória intitulada "Plantas do Certāo do Gram Pará por Joăo Pedro Ribeiro constando fundaméntalmente de desenhós seguidos de "regras pelas quais se devem estampar as ervas medicinais e fazer recolher as suas ramas e raf- 
zes..." A classificação é geografica pelo nome da povoação. s.d. 75p. ilus. col. aquar. (Códice. $350 \mathrm{~mm}$ x $230 \mathrm{~mm}$ ).

Ms 627

70 - "Memória sobre as árvores de construçáo consideradas pelos caracteres botanicos por Balthasar da Silva Lisboa, na qual estuda as espécies: "sucupira, bignomia ou pao d'alho, sapucaia, quiri, pekea, decandria, angelim, bity, paus d'oleo (copaiba) jetahy amarelo, oiticica, pindalba, jacarandá, vinhático, ibirapitanga" etc. s.d. 75p. (Códice. $330 \mathrm{~mm} x$ $220 \mathrm{~mm}$ ).

Ms 17.7

71 - "Memória sobre os cortes das arvores do Brasil e os melhores meyos de preparar as suas maneiras para mais deixarem conservar as suas boas qualidades" por Balthasar da Silva Lisboa. s.d. 41p. (Códice. $330 \mathrm{~mm}$ x $220 \mathrm{~mm}$ ).

Ms 17.8

72 - Relaçăo intitulada "Breve notícia das Principais Aves que ha em o estado do Brazil que pertence a Coroa de Portugal" contendo descriçăo de 53 espécies, por ordem alfabética do nome em portugués e trazendo caracteristicas de cada uma como tamanho, cores, hábitos, etc. s.d. 299p. (Códice. $219 \mathrm{~mm} \times 160 \mathrm{~mm}$ ).

Ms 332

\section{VI - INDfGENAS}

73 - Carta do Padre Antonio Vieira a uma amigo reiterando a sua fé e dedicaçáo a Deus, a seu trabalho missionário no Brasil, náo obstante as hostilidades, perseguiçóes e agressóes que vinha sofrendo. Maranhăo, 26 de maio de 1653. 6p. (Maço. 273mm x 215mm).

Ms 831

74 - Informaçáo em quatro capitulos do Padre Antonio Vieira descrevendo a "pouca justiça" com que tinha sido tratado um grupo de índios cativos no Maranhāo, detalhando a sistemática das entradas e dos resgates, propugnando pelo cumprimento da legislaçăo indigenista. $1655.86 \mathrm{p}$. (Maço. 278mm x 213mm).

Ms 829

75 - Estudo do Padre Antonio Vieira no qual apresenta detalhadas sugestoes quanto ao "modo com que se ha de 
governar o gentio do Maranhăo e Pará", tanto no que se referia ao temporal como ao espiritual: como se deveria organizar as entradas no sertao e como proceder com os indigenas resgatados, sugerindo formas de trabalho, assim como as de organizar as aldeias e a assitencia espiritual a elas . s.d. 26p. (Maço. 271mm x 213mm).

Ms 828

76 - Parecer do Padre Antonio Vieira a respeito dos meios que o governo portugues deveria utilizar para a conservaçáo, aumento e defesa do Maranháo s.d. (c. 1650-1670). 19p (Maço. 273mm x 213mm).

Ms 832

77 - "Memória sobre os homens selvagens da América Meridional que serve de introduçam as viagens por Antonio Pires da Silva Pontes Leme. Primeiro Tenente do Mar da Armada Real, Doutor em Astronomia e correspondente da Real Academia de Lisboa. Anno 1792" . 6p. (Codice. 330mm x 220mm).

Ms 17.37

78 - "Dicionário da língua falada por indios do Brasil contendo no fim vários textos principalmente os catecismos escritos na mesma língua" seguido de textos doutrinários apropriados para serem veiculados junto aos indfgenas, assim como de poesias de caráter laudatório aos Santos e a Nossa Senhora, em Ifngua tupi, sem autor e sem data. 109p. (Codice. $215 \mathrm{~mm} \times 153 \mathrm{~mm}$ ).

Ms 569

INDICE

ABRANTES, Marques de - 55,56

ACIDO NITROSO - 63

AÇÚCAR - 33

ÁFRICA - 50

AGRICULTURA - 67

ALFÂNDEGA

- de Lisboa - 48

ALGODÃO - $\overline{64}$

ALMEIDA, Francisco José de Lacerda e - 18, 19

ALMEIDA, Joåo Mendes de - 47

ALMEIDA, Luis Beltrâo de Gouveia d' - 7

ALTO, Cipriano Pereira do -24 
Da. AMÉLLA, Imperatriz do Brasil - 41, 46, 58

ARAGĀO, Egas Moniz Barreto de - 10

ARANHA, Pedro Wenceslao Brito - 13

ARAÚJO, Felipe Ferreira - 58

ÁRVORES FRUTIFERAS - 68

ASSUMAR, Conde de (D. Pedro de Almeida ) - 28B

AVES - 72

BAHIA - $4,12,26,32,50,51,62$

BARBACENA, Marques de (Felisberto Caldeira Brandt) - 37,46

BARROS, Joāo de - 11

BETANCOURT, Jorge de Sa - 64

BIBLIOTECA NACIONAL (Brasil) - 13

BRANDÄO, Frei Caetano - 23

BRAUN, Joåo Vasco Manoel de - 15, 17

BUENOS AIRES - 7, 30, 32, 35, 48

CABO VERDE - 14

CABRAL, Pedro Álvares - 11, 57

CAMAMU - 64

CÂNHAMO - 72A

CASA DA FNDIA - 48

CASTANEDA, Fernăo Lopes de - 11

CASTELO-BRANCO, José Barbosa Canaes de Figueiredo - 27

CEARÁ - 27, 28A

COCHONILHA - 61

COLONIA DO SACRAMENTO - 30,31, 32, 48

COMERCIO - 44, 52

CONJURAÇÕES - 6

CORREIA, Padre Francisco - 10

CORRESPONDENCIA DIPLOMÁTICA - 39, 42, 54, 55

COSTA BRASILEIRA - descriçăo geográfica - 14

COURO - Transporte - 48

CRIAÇÃO DE VILAS - 57

CUIABA - Minas de ouro - 59

CUNHA, D. Luís da - 31

DESCOBRIMENTO DO BRASIL - 1,11,57

DEUS, Frei Gaspar da Madre de - 5

DIAMANTES - 47

EMIGRAÇĀO E IMIGRAÇĀO - 43, 44, 45

ENGENHOS DE AÇÚCAR - 24

ESCHWEGE, Barăo de - 66

EVANGELIZAÇĀO - 78

EVRARD, Dupré - 14 
FAUNA - 1,9,28A

FERREIRA, Silvestre Pinheiro - 58

FERRO - 25

FLORA - 1, 9, 28A, 60, 66, 68, 69, 70, 71

FRANÇA - 14, 29, 39, 55

GANDAVO, Pero de Magalhães - 1,2

GEOGRAFIA

$$
\begin{aligned}
& \text { Amazonas }-15,24,28 \mathrm{C} \\
& \text { Bahia }-26 \\
& \text { Ceará }-27 \\
& \text { Maranhão }-9 \\
& \text { Mato Grosso }-16,18,19 \\
& \text { Pará - 15, 16, 17, 23, 28C } \\
& \text { Parába - } 3 \\
& \text { Pernambuco - 20, } 21 \\
& \text { São Paulo - 18, 25, 28B } \\
& \text { Rio Grande do SuI - } 22 \\
& \text { Rio de Janeiro - 28B } \\
& \text { Costa Brasileira - } 14 \\
& \text { Minas Gerais - 28B }
\end{aligned}
$$

GIRALDES, J. P. Casado Cardoso (Coronel) - 7, 57

GOIAS, 8

GOIS, Joåo Machado - 28A

ILHA DA MADEIRA - 14

ILHÉUS - 26

INCONFIDENCIA MINEIRA - 6

INDEPENDÊNCIA DO BRASIL - 38

INDIGENAS $-3,74,75,77,78$

INDÚSTRIA - 67

INHAMBUPE, Marques de (Antonio Luiz Pereira da Cunha) - 35

INSTITUTO HISTÓRICO E GEOGRÁFICO BRASILEIRO - 13 INVASÄO ESPANHOLA EM SANTA CATARINA - 34

INVASĀO HOLANDESA NA BAHIA - 4
JESUITAS - 73, 74, 75, 76
D. JOÄO V - 29, 47, 50
D. JOĀO VI - 12,53

KEULEN, Joanes Von -20 
LAGO, Antonio Bernardino Pereira do - 9

LAVOURA - 64

LEME, Antonio Pires da Silva Pontes - 77

Da. LEOPOLDINA, Imperatriz do Brasil- 35

LINGUAS INDIGENAS - 78

LISBOA, Balthasar da Silva $-70,71$

MACAPA - 17

MACEDO, Duarte Ribeiro de - 60

MACEIO, Marques de - 39

MACDONALL, Robert - 34

MADEIRAS - 62, 66, 68, 70,71

MARANHĀO $-9,50,63,74,75,76$

Da. MARIA I - 34

Da. MARIA II - 36, 37

MATO GROSSO

- Capitania - 16, 18, 19

D. MIGUEL, infante de Portugal - 36, 40, 46

MINAS GERAIS - 47, 49, 50

MINERAÇĀO - 33, 50, 59

MONTEZUMA, Francisco Ge de Acaiaba de - 42

NAVEGAÇÃO - 24, 44

ORDONHEZ, Diogo de Toledo Lara - 59

PARÁ - 15, 16, 17, 23, 28C, 69, 75

PARAIBA $-3,50$

PEDRA BONITA - 10

D. PEDRO I, Imperador do Brasil e Rei de Portugal (D. Pedro IV)$36,38,40,41,42,46,58$

D. PEDRO II, Rei de Portugal - 50

PEREIRA, Joaquim José - 63

PERIODO REGENCIAL - 38, 39, 57

PERNAMBUCO - 10, 20, 21, 49, 50

PIAUI - 50, 63

PINHO, José Pereira - 21

PRIMEIRO REINADO - 37, 46, 55, 56

PROVINCIA CISPLATINA - 35

QUIMICA - 63

QUINA - 65 
REAL FÁBRICA DE FERRO DE SÃO JOÃO DE IPANEMA - 25

REBOXO, Theodosio da Silva - 62

RECENSEAMENTO - 51

REIS, Manuel Muniz do Couto - 22

RELAÇŌES - Portugal-Brasil - 43, 44, 45

- Portugal-Espanha - 30,31,32

RESENDE, Marques de - 35 36, 37, 38, 39, 40, 41, 42, 46, 54, 55

RIBEIRO, Joð์o Pedro - 69

RIO AMAZONAS - 15, 24, 29

RIO DA PRATA

RIO DE JANEIRO $-28 \mathrm{~B}, 50,65$

- Política - 30, 31, 32, 35, 54

RIO GRANDE DO SUL - 7,22,50

RIO NEGRO (CAPITANIA) - 18

RIOS - 15, 19, 24, 28, 29

ROTEIROS DE VIAGEM - 14, 15, 16, 18, 20, 21, 28A, 28B, $28 \mathrm{C}$

SALVADOR

SANTA CATARINA - 32, 34

- Populaçáo - 51

SANTO AMARO (CAPITANIA) - 4

SĀO LUIS DO MARANHĀO - 9

SẢO PAULO

- Capitania - 5, 18, 25, 28B

SĀO VICENTE (Capitania) - 7

SARMENTO, Christovăo Pedro de Moraes (Barão da Torre de MonCOrvo) 41

SEBASTIANISMO - 10

SERGIPE - 50

SERVIÇO DIPLOMÁTICO- 46, 55, 56

SERRO DO FRIO - 47,50

SILVA, José Bonifácio de Andrada e - 38

SILVEIRA, Francisco José da - 65

SOCIEDADE AUXILIADORA DA INDÚSTRIA NACIO-

NAL - 13

SOUZA, José Patrício- 20

SOUZA, Luis Antonio da Silva e -8

SILVA, José Telles da - 28A

TABACO - 33

TELLES, Antonio Carlos Moreira - 43, 44, 45

TRANSFERENCIA DA FAMILIA REAL -12

TRANSPORTE DE MERCADORIAS - 52

TRATADO DE UTRECHT - 29, 30, 31, 32

TUPI (Lingua) - 79 
VALENCIA Y GUSMAN, Juan de -4

VARNHAGEN, Francisco Luis Guilherme - 54

VIEIRA, Padre Antonio - 73, 74, 75, 76

VITERBO, Francisco Marques de Souza - 11

Recebido em 25/10/89 